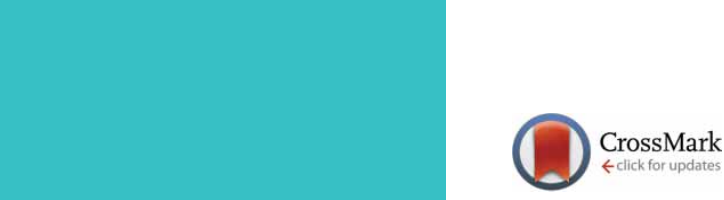

\title{
Annual changes in the prevalence of asthma may be related to air pollution in Fukuoka: 29 years of observation
}

\author{
Hiroshi Odajima, Toshiaki Kawano, Masatoshi Wakatsuki, Yuko Akaminea, \\ Koki Okabe, Tuyoshi Oki, Hiroshi Matsuzaki, Yoko Murakami, Mihoko Iwata, \\ Naohiko Taba, Chikako Motomura, Satoshi Honjo and Takahito Ninomiya
}

Affiliation: Dept of Pediatrics, National Hospital Organization Fukuoka National Hospital, Fukuoka, Japan.

Correspondence: Hiroshi Odajima, Dept of Pediatrics, National Hospital Organization Fukuoka National Hospital, 4-39-1 Yakatabaru, Minami-ku, Fukuoka city, Fukuoka, 811-1394, Japan. E-mail: odajihabiglobe.ne.jp

ABSTRACT The relationship between the annual changes of the prevalence of bronchial asthma (BA) and that of concentrations of air pollutants has not been reported.

We studied the annual prevalence of BA, remission of BA, and wheeze in children at the same five elementary schools in Fukuoka city, Japan, in October to November from 1988 to 2016 by the same methods using the same questionnaire.

Annual changes in the prevalence of asthma among boys were related to changes in the air concentrations of $\mathrm{NO}(\mathrm{r}=0.708), \mathrm{NO}_{2}(\mathrm{r}=0.665)$ suspended particulate matter (SPM) $(\mathrm{r}=0.803)$, and smoking rate $(r=0.741)$, but there were no such relationships among girls. Annual changes in the prevalence of wheeze were related to changes of $\mathrm{NO}, \mathrm{NO}_{2}, \mathrm{SPM}$, and smoking rate among boys and girls (NO: $r=0.650,0.660 ; \mathrm{NO}_{2}: \mathrm{r}=0.556,0.490$; SPM: $\mathrm{r}=0.582,0.518$; smoking rate: $\mathrm{r}=0.656,0.593$, respectively) (all of the above are significant with $\mathrm{p}<0.05$ ). There was no relationship between remission of BA and any of the pollutants.

Annual changes in the prevalence of boys' BA and boys' and girls' wheeze among first-grade children (age 6 or 7 years) in Fukuoka were correlated with changes in the concentration of air pollutants (SPM, $\mathrm{NO}, \mathrm{NO}_{2}$ or smoking rate).

Recent decrease of asthma prevalence in this area might be related to the decreasing tendency of air pollutant concentration. The causal relationship between the two will need to be verified in the future

@ERSpublications

Annual changes in the prevalence of child asthma in Fukuoka are correlated with those in the concentration of air pollutants (SPM, etc.). A recent decrease of asthma prevalence might be related to the decreasing concentration of air pollutants. https://bit.ly/2RlYXfu

Cite this article as: Odajima $\mathrm{H}$, Kawano T, Wakatsuki M, et al. Annual changes in the prevalence of asthma may be related to air pollution in Fukuoka: 29 years of observation. ERJ Open Res 2020; 6: 00166-2020 [https://doi.org/10.1183/23120541.00166-2020].

Received: 3 April 2020 | Accepted: 3 April 2020

Copyright $\odot$ ERS 2020. This article is open access and distributed under the terms of the Creative Commons Attribution Non-Commercial Licence 4.0. 


\section{Introduction}

Recently, the prevalence of asthma has been decreasing in some areas, especially those where a high prevalence was previously reported [1]. We have reported that the prevalence of asthma has been decreasing in west Japan, including Fukuoka city, for the past 10-20 years [2].

It was reported that the atmospheric concentration of suspended particulate matter (SPM) is high in the Japanese island of Kyushu [3]. The prevalence of asthma in Fukuoka city, Kyushu is at a relatively high level for Japan, with Kyushu having both a high prevalence of bronchial asthma (BA) and high atmospheric levels of $\mathrm{PM}_{2.5}$ and SPM [3].

However, the relationship between annual changes in the prevalence of asthma among children and the concentrations of air pollutants has received little attention recently in Kyushu or Japan, or elsewhere in the world.

We hypothesised that annual changes in the levels of air pollutants in a particular region could be associated with annual changes in the prevalence of BA.

The aim of this study was to clarify the relationship between annual changes in the prevalence of BA, wheezing, or remission of BA and those of the concentrations of air pollutants in children.

\section{Methods}

We investigated the relationship between the annual changes in the prevalence of $\mathrm{BA}$, wheezing, or remission of BA and those of the concentration of nitrogen monoxide (NO), nitrogen dioxide $\left(\mathrm{NO}_{2}\right), \mathrm{SPM}$ or Japanese smoking rate among the children in the first grade in the five elementary schools in Fukuoka (Kyushu, Japan) by the same methods for 29 years.

\section{Subjects}

We studied the prevalence of BA, wheezing, and remission of BA among first-grade children at the same five elementary schools every October to November from 1988 through 2016, except in 4 years (1997, 2000, 2002, and 2008) using the same diagnostic criteria and the same questionnaire. These 4 years were excluded because different forms of research were conducted as a part of other research. The questionnaire was completed by the caregivers of the subjects and collected by teachers at the schools in all surveys.

Using the prevalence of BA, remission of BA and wheezing obtained in this continued survey (table 1), the relationship with air pollutant concentration every year (table 2) was examined.

\section{Questionnaire (definitions of asthma and other diseases)}

A Japanese translation the American Thoracic Society-Division of Lung Diseases (ATS-DLD) [4] questionnaire ( J-ATS-DLDQ) was used. Definitions of diseases were consistent across all surveys.

\begin{tabular}{|c|c|c|c|c|}
\hline & & Male & Female & Total \\
\hline \multicolumn{5}{|c|}{ Responders to questionnaire } \\
\hline & Number (in 25 years) & 6222 & 6389 & 12611 \\
\hline & Mean \pm SD (per year) & $248.9 \pm 27.6$ & $255.6 \pm 71.6$ & $504.4 \pm 87.2$ \\
\hline & Median & 241.5 & 238 & 488 \\
\hline & Min & 195 & 212 & 587 \\
\hline & Max & 295 & 293 & 407 \\
\hline \multicolumn{5}{|l|}{ Prevalence (\%) } \\
\hline \multirow[t]{3}{*}{ Asthma } & Median & 6.24 & 3.83 & 5.20 \\
\hline & Min & 2.98 & 1.38 & 2.39 \\
\hline & Max & 9.42 & 7.27 & 8.35 \\
\hline \multirow[t]{3}{*}{ Remission of asthma } & Median & 1.52 & 1.05 & 1.53 \\
\hline & Min & 0.00 & 0.41 & 0.48 \\
\hline & Max & 4.44 & 2.89 & 2.87 \\
\hline \multirow[t]{3}{*}{ Wheeze } & Median & 7.13 & 5.45 & 6.14 \\
\hline & Min & 0.98 & 0.00 & 0.72 \\
\hline & Max & 12.41 & 10.88 & 11.23 \\
\hline
\end{tabular}




\begin{tabular}{|c|c|c|c|c|}
\hline & $\mathrm{SPM} \mathrm{mg} \cdot \mathrm{m}^{-3}$ & NO ppb & $\mathrm{NO}_{2} \mathrm{ppb}$ & Smoking rate $\%$ \\
\hline Median & 0.033 & 0.023 & 0.026 & 30.9 \\
\hline Min & 0.020 & 0.007 & 0.015 & 19.3 \\
\hline Max & 0.043 & 0.037 & 0.030 & 36.9 \\
\hline
\end{tabular}

Children who met all of the following six criteria were regarded as having BA, whereas subjects who met the following criteria 1-5, but not criterion 6 , were classified as having remission of BA: 1) experience with attacks of wheezing and/or shortness of breath; 2) two or more attacks in the past; 3) diagnosis of BA, asthmatic bronchitis, or paediatric asthma by a doctor; 4) audible wheezing during an attack; 5) shortness of breath and wheezing during an attack; and 6) had such an attack (or symptoms) or received treatment for $\mathrm{BA}$, asthmatic bronchitis, or paediatric asthma in the past 2 years.

Subjects who met the following three criteria, but not the criteria for BA or remission of BA, were defined as having wheezing: 1) occasional wheezing; 2) wheezing symptoms in conjunction with a common cold; and 3) wheezing twice or more in the past 2 years.

\section{Concentrations of air pollutants}

We obtained data on air pollutants from the website of the National Institute for Environmental Studies [5]. The average annual concentrations of $\mathrm{NO}, \mathrm{NO}_{2}$, and SPM from 1988 through 2016 were calculated from the daily average values obtained at six monitoring stations in Minami Ward and Chuo Ward of Fukuoka city, where the five schools were located. The maximum distance between the schools and monitoring stations was less than $7 \mathrm{~km}$. We obtained data from the Japanese tobacco industry on the annual trend of smoking rate.

\section{Statistical analysis}

Examination of the prevalence of $\mathrm{BA}$, remission of $\mathrm{BA}$, or wheezing and the concentration of air pollutants for 29 years excluding 4 years did not show any significant outliers (tables 1 and 2).

There was a correlation between air pollutants (data not shown). Spearman's rank correlation analysis was used to assess the association between air pollutant levels and the prevalence of each diagnosis. Statistical analysis was performed with R-3.6.1 (Foundation for Statistical Computing, Vienna, Austria).

A p-value $<0.05$ (two tailed) was considered to indicate a statistically significant difference.

This study was approved by the ethical committee of the National Hospital Organization Fukuoka National Hospital (authorisation no. 29-24).

\section{Results}

From 1988 to 2016, a total of 12611 caregivers of children in the first grade (6222 boys and 6637 girls) answered the questionnaire. The average number of children per year was $493.8 \pm 46.7$. Table 1 shows the median, minimum, and maximum values of the prevalence of $\mathrm{BA}$, remission of $\mathrm{BA}$, and wheezing obtained over the past 25 years. The characteristics of the air pollutants are shown in table 2 .

Annual changes in the prevalence of BA among boys were related to changes in the concentrations of NO $(\mathrm{r}=0.708, \mathrm{p}<0.01), \mathrm{NO}_{2}(\mathrm{r}=0.665, \mathrm{p}<0.01), \mathrm{SPM}(\mathrm{r}=0.803, \mathrm{p}<0.01)$, and smoking rate $(\mathrm{r}=741, \mathrm{p}<0.01)$, whereas there were no such relationships among girls. Annual changes in the prevalence of wheezing were related to those of $\mathrm{NO}(\mathrm{r}=0650, \mathrm{p}<0.01), \mathrm{NO}_{2}(\mathrm{r}=0.556, \mathrm{p}<0.01), \mathrm{SPM}(\mathrm{r}=0.582, \mathrm{p}<0.01)$, and smoking rate $(\mathrm{r}=0.656, \mathrm{p}<0.01)$ among boys and among girls $(\mathrm{r}=0.660, \mathrm{p}<0.01 ; \mathrm{r}=0.490, \mathrm{p}<0.05 ; \mathrm{r}=0.518, \mathrm{p}<0.01$, respectively). There was no relationship between remission of BA and any of the pollutants (table 3 and figures 1-3).

Figure 4 displays the annual changes in the concentration of SPM versus the annual changes in the prevalence of BA among boys.

\section{Discussion}

This study revealed a significant correlation between the atmospheric concentrations of $\mathrm{NO}, \mathrm{NO}_{2}, \mathrm{SPM}$ or smoking rate and the prevalence of BA among boys, as well as the concentrations of $\mathrm{NO}, \mathrm{NO}_{2}, \mathrm{SPM}$, or smoking rate and the prevalence of wheezing among both boys and girls. 
TABLE 3 Correlation coefficient between the prevalence of each disease and the concentration of air pollutants in the study area or smoking rate in Japan

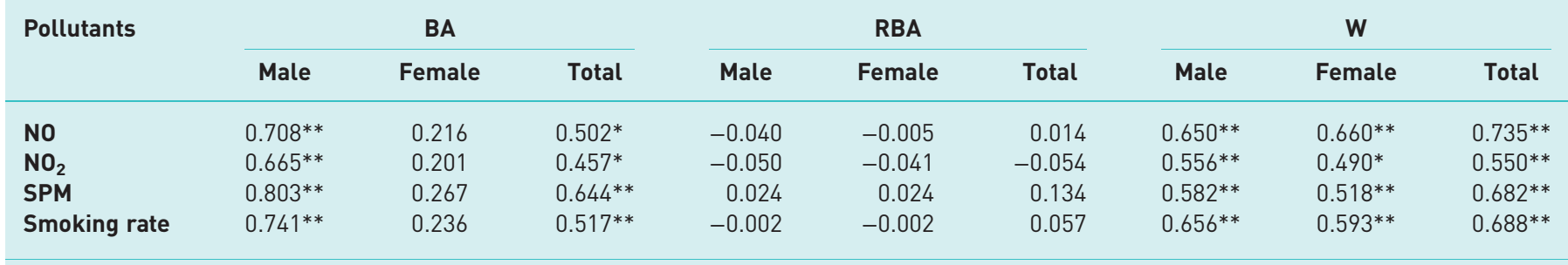

Correlations are calculated according to Spearman's correlation test. BA: bronchial asthma; RBA: remission bronchial asthma; W: wheeze; NO: nitrogen monoxide; $\mathrm{NO}_{2}$ : nitrogen dioxide; SPM: suspended particulate matter. Spearman's rank correlation analysis; *: $p<0.05$ (two tailed); ${ }^{* *}: \mathrm{p}<0.01$ (two tailed).

There have been many reports about the relationship between air pollutants and BA [6-9] or respiratory diseases. In Japan, Kyushu has a high prevalence of BA and high atmospheric concentrations of SPM or $\mathrm{PM}_{2.5}$ [3] but there has been a declining trend over the past 10-20 years [2]. This is similar to reports in other regions [1]. However, little is known with regard to the relationship between annual changes in the prevalence of BA and changes in the concentration of air pollutants, especially over a long period. In this study, we attempted to clarify relationships between the concentrations of air pollutants and the prevalence of BA, remission of BA, or wheezing in one area of Kyushu over a long period.

\section{Air pollution in Fukuoka city}

Fukuoka city is located in the north-western part of Kyushu, with its northern region facing the Genkai Pass, and is located in the centre of the half-moon-shaped Fukuoka Plain surrounded by mountains. The climate is relatively warm and is classified as a Japanese seaside-type climate. The elementary schools surveyed in this study were located in Minami Ward and Chuo Ward. The national road, Route 385 runs north to south, and the Fukuoka Outer Ring Road runs through the centre. These features of the environment have not changed significantly in the last 30 years.

There have been some reports about the relationship between the air pollutants and asthma in this area, such as hospital admissions [10, 11], exacerbation of BA [12, 13], and effect changes of the peak expiratory flow rate [14]; however, the results of these studies are not always consistent.
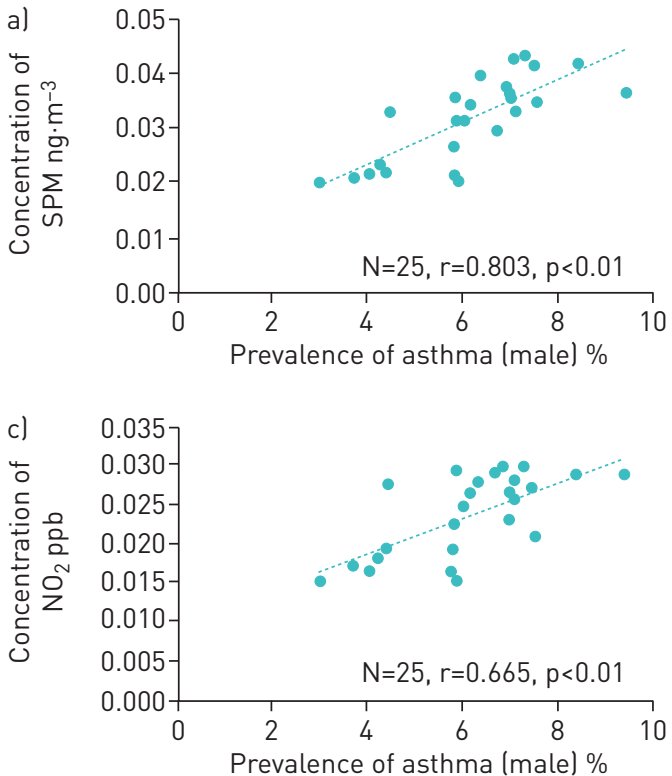
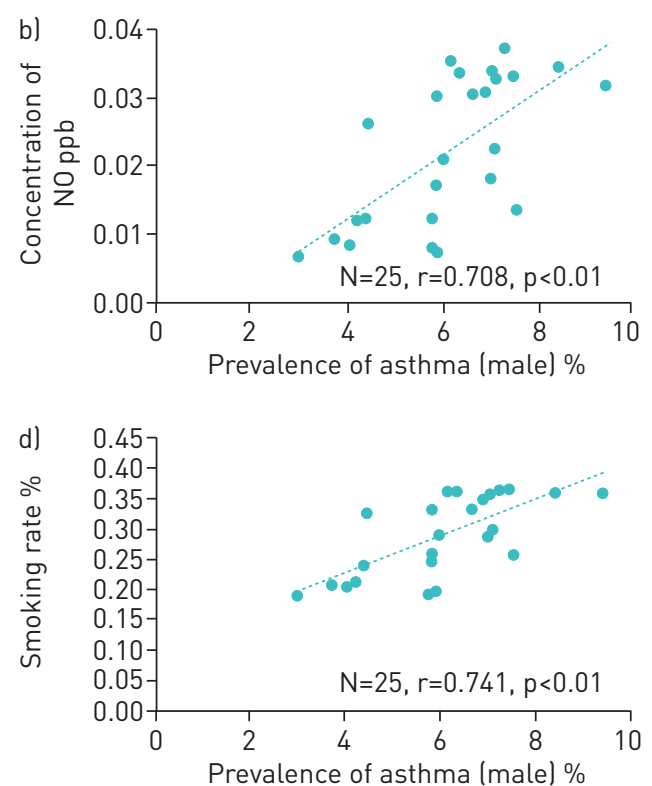

FIGURE 1 Prevalence of asthma (male) and concentration of a) SPM, b) NO, c) $\mathrm{NO}_{2}$, or d) smoking rate. SPM: suspended particulate matter; $\mathrm{NO}$ : nitrogen monoxide; $\mathrm{NO}_{2}$ : nitrogen dioxide. Spearman's rank correlation analysis. In boys, prevalence of asthma is significantly correlated with any pollutant. Such a relationship was not seen in girls. 


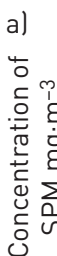

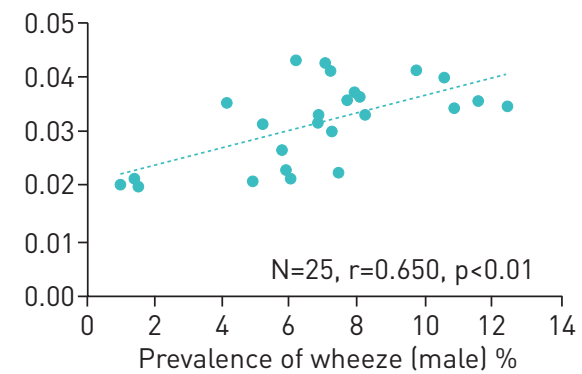

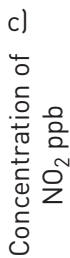

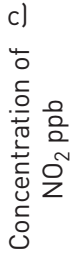

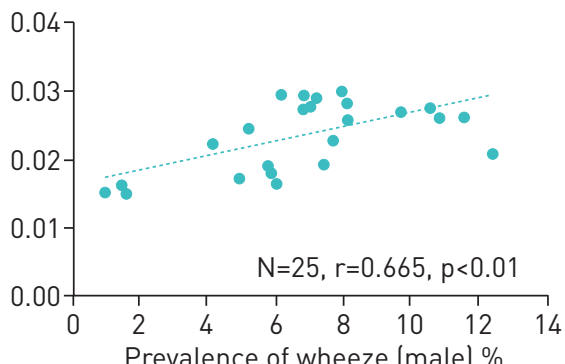

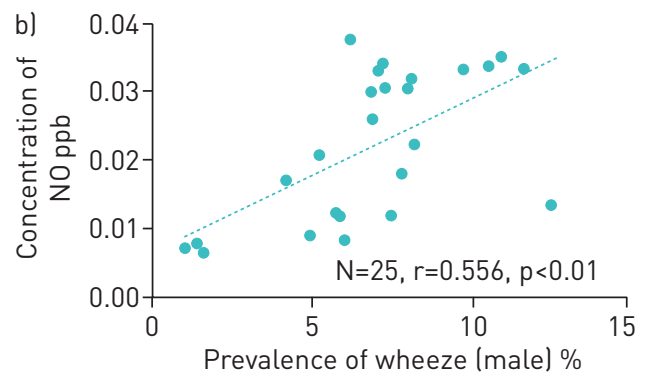

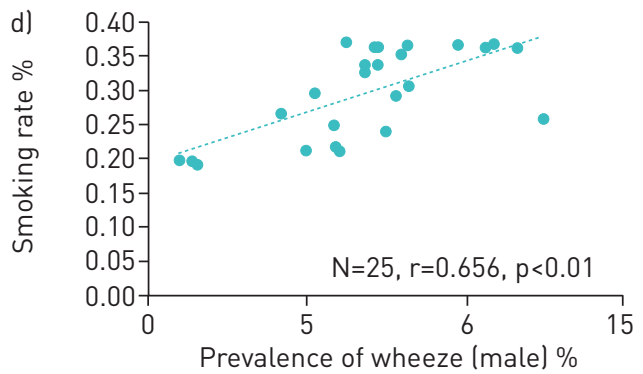

FIGURE 2 Prevalence of wheeze (male) and concentration of a) SPM, b) $\mathrm{NO}, \mathrm{c}$ ) $\mathrm{NO}_{2}$, or d) smoking rate. Prevalence of wheeze is significantly correlated with any pollutant. SPM: suspended particulate matter; NO: nitrogen monoxide; $\mathrm{NO}_{2}$ : nitrogen dioxide.

There are many potential pollutants in Japan. In this study, we selected $\mathrm{NO}, \mathrm{NO}_{2}, \mathrm{SPM}$, and smoking rate as the air pollutants for examination because these pollutants have been measured continuously over a long period. Sulfur dioxide has been studied in the past, but recently the concentration was usually below the environmental standard and many authors did not report a relation with the prevalence of BA or respiratory diseases [6]. Accordingly, we examined the air pollutants mentioned above.

The health effects of air pollutants should be measured with a device worn on the individual's body. Also, measurement should be made as close to the living environment as possible. However, our research started when these methods were not available. Therefore, in order to maintain consistency with the past, we decided to use measured values in a relatively narrow range, surrounding individuals as in this case. In the future, it will be necessary to consider the examination in a precise manner.
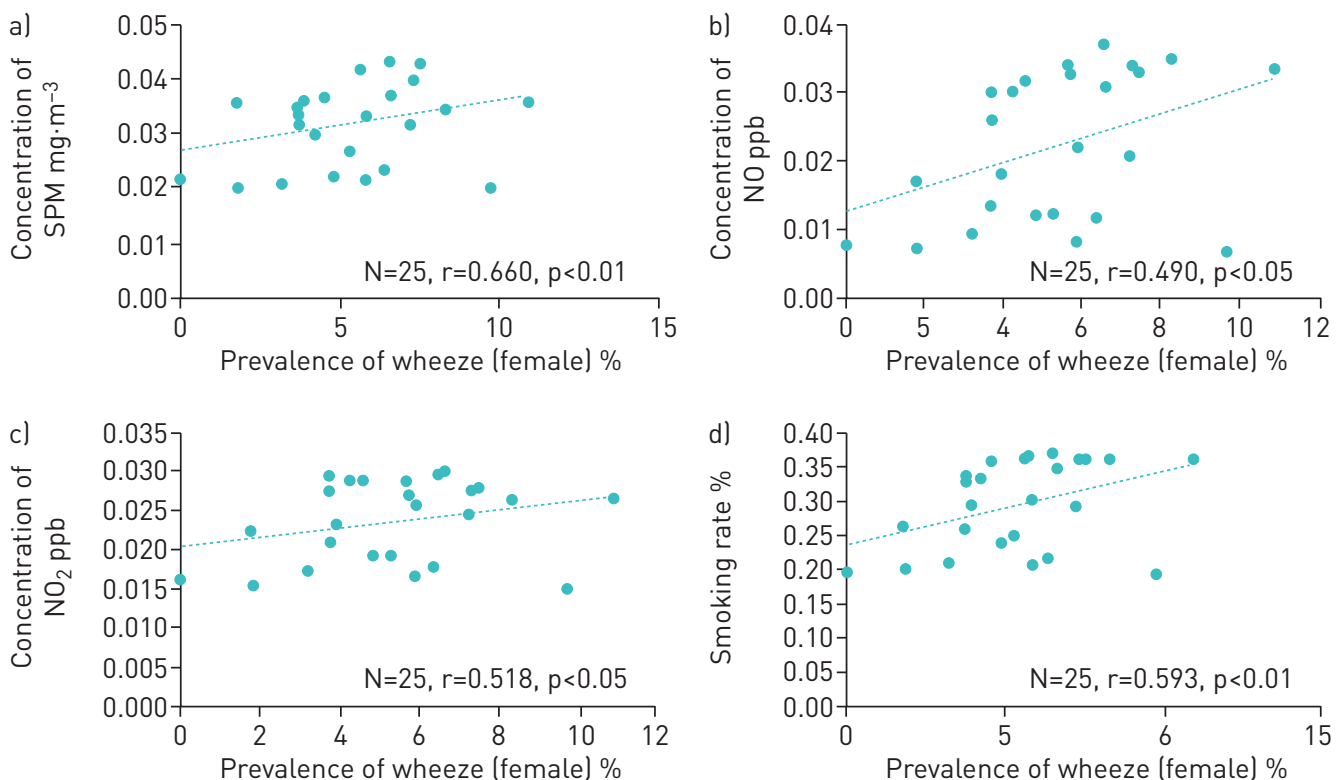

FIGURE 3 Prevalence of wheeze (female) and concentration of a) SPM, b) NO, c) $\mathrm{NO}_{2}$, or d) smoking rate. Prevalence of wheeze is significantly correlated with any pollutant. SPM: suspended particulate matter; NO: nitrogen monoxide; $\mathrm{NO}_{2}$ : nitrogen dioxide. 


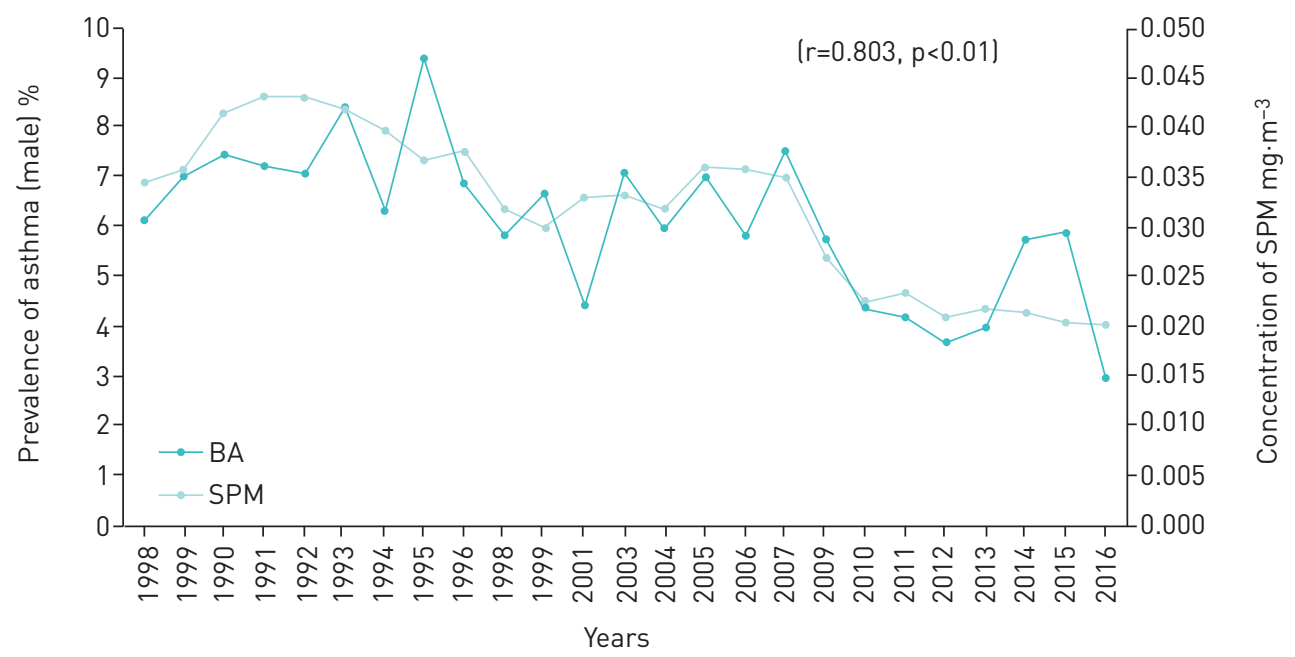

FIGURE 4 SPM concentration and prevalence of asthma. There is a statistically significant relationship between the annual changes of the concentration of SPM and the prevalence of asthma in male children in the first grade of elementary school. SPM: suspended particulate matter.

Prevalence of $B A$, remission of $B A$, and wheezing in Japan

We have previously studied the prevalence of asthma at 10-year intervals (1982, 1992, 2002, and 2012) at the same schools in the same area by standardised methods using the same questionnaire (J-ATS-DLDQ) [15]. In this study, we used the same questionnaire as in those previous studies. Our other studies revealed an increasing trend from 1982 to 2002 [16] using the same questionnaire. However, there was a decrease from 2002 to 2012. This decrease in the prevalence of asthma has also been identified by other sources by other questionnaires, such as the 2018 School Health Statistics [17].

Recent epidemiological studies in children have often used the international study of asthma and allergies in childhood (ISAAC) questionnaire, but we used the J-ATS-DLDQ to maintain consistency with data obtained before the ISAAC questionnaire was developed. The questionnaire that we used, J-ATS-DLDQ, was translated from the ATS-DLD by the Japanese Ministry of the Environment and had been widely used in Japan. We also participated in the ISAAC phase I and III survey in Fukuoka city in 1997 and 2002 [18]. The main difference in the questionnaires between ISAAC and ATS-DLD is whether dyspnoea is included in the diagnostic criteria, which results in differences in frequency. Past studies $[2,4,15,16,19]$ have shown that stable prevalence can be obtained even in cross-sectional and inter-annual surveys. Therefore, we have determined that a temporal comparison is possible.

Relationship between $B A$, remission of BA or wheezing and air pollution

We examined the relationship between the prevalence of asthma and the concentrations of several air pollutants. There have been many reports about the relationship between asthma and air pollution, but the results of these studies were not always the same, possibly because most studies were done over a wide geographical area and at various periods. In contrast, we studied the relationship every year in the same limited area and repeated our investigation over a long period with the same methods from 1988 through 2016 (except for 1997, 2000, 2002, and 2008). It was considered that this approach was suitable for studying the effects of annual changes of pollutants on respiratory diseases in children.

Recently, air pollution has been decreasing in Japan. Surveillance data show that Kyushu has the highest prevalence of BA in Japan [3]. The reasons for this high prevalence of BA are not clear. This was one of the reasons why we planned the present study, (i.e. the high concentrations of air pollutant and high prevalence of BA in our area seemed to be suitable for assessing the influence of annual changes because the effects of SPM might be significant at high concentrations).

There have been many reports about the relationship between the prevalence of BA and air pollution, but few regarding the relationship between annual changes in the prevalence of BA and concentrations of air pollutants. In this study, we used the same diagnostic criteria (J-ATS-DLDQ).

In the surveys by the Japanese Ministry of the Environment, concentrations of $\mathrm{NO}_{\mathrm{x}}\left(\mathrm{NO}\right.$ and $\left.\mathrm{NO}_{2}\right)$ and $\mathrm{SO}_{2}$ were below environmental standards and no relationship with respiratory disease has been shown recently [3]. The $\mathrm{NO}_{\mathrm{x}}$ concentration has been relatively high compared to that of $\mathrm{SO}_{2}$ in Japan, and there have been some reports of a relationship between $\mathrm{NO}_{\mathrm{x}}$ and $\mathrm{BA}$, so we studied the relationship between 
$\mathrm{NO}_{\mathrm{x}}$ and the prevalence of respiratory disease instead. We previously reported that persistence of asthma symptoms between 1.5 and 3 years was significantly associated with outdoor concentrations of $\mathrm{NO}_{\mathrm{x}}$, as estimated by a dispersion model [20], suggesting that the relationship between $\mathrm{NO}_{\mathrm{x}}$ and the prevalence of $\mathrm{BA}$ and wheezing in the present study might be related to this effect of $\mathrm{NO}_{\mathrm{x}}$ on $\mathrm{BA}$.

Annual changes in the prevalence of BA among boys were significantly related to that in concentrations of SPM (figure 4, $\mathrm{r}=0.803, \mathrm{p}<0.01$ ). However, this study is not an analysis using cross-sectional data, and it is considered that further studies are needed in the future.

\section{Limitations}

A potential limitation of this study was the sample size. This study focused on a small geographical area, so it might have limited generalizability, although this reduced the influence of environmental geographic variation. Therefore, research is also needed to investigate areas where changes in background factors other than pollutants are small. However, this study has been conducted at the same schools by the same methods and in the same season for about 30 years. The data from that period are important because overall air pollutant levels have decreased recently and variations in the concentrations of pollutants have become smaller so the effects might not be so significant. We have data from the time when air pollutant levels were still high about 30 years ago up to the present when levels are lower, so this study provides important information on the effects of pollutants.

Another potential limitation of the current study is that we only assessed the effects of air pollutants on the prevalence of asthma, which is also influenced by other factors. In Fukuoka city, we have previously studied the relationship between the prevalence of asthma and the weather, Asian dust, smoking rate, and air pollutants [11, 21], as well as obesity [22]. The results of these studies were not all the same. Although we did not consider these points in this study, there was a strong relationship between changes in the concentrations of air pollutants, especially SPM, and changes in the prevalence of asthma.

What we identified in this study was the relationship between the prevalence of asthmatic boys and SPM or other air pollutants concentrations in the time series, and the causal relationship between the two will need to be verified in future case-control and cohort studies.

\section{Sex differences}

Our study revealed a difference in the relationship between the prevalence of BA and air pollutants among boys and girls. In grade 1, the prevalence of asthma is reported to be about 1.5-times higher in boys than in girls [3], suggesting that boys might be more susceptible to air pollutants. The prevalence of infectious diseases is also known to be higher among boys compared to girls, and an infected airway can more easily be affected by pollutants. Recurrent respiratory tract infections can lead to airway hyperreactivity and asthma, which may explain why boys show a higher prevalence of asthma, and higher relationship.

A sex difference in the prevalence of wheezing was not recognised in this study. According to diagnostic criteria in this study, patients with BA have dyspnoea, but wheezing does not always coincide with dyspnoea, so the symptoms of BA are more severe. Thus, the sex difference in the prevalence of BA and wheezing might be related to differences in the severity of symptoms in boys and girls.

This study involved an annual assessment of the relationship between the prevalence of BA or wheezing and air pollutants over about 30 years in children at the same schools in Japan, using the same methods and same questionnaire. Despite these strengths, the study was carried out in only one city (Fukuoka, Japan), which might be a weak point. However, the results were significant, and the relationship was especially significant in boys, as shown in figure 4 or table 3 . Therefore, it is inferred that the background factors of the survey target were relatively constant, and it was estimated that there was a strong association between air pollutants and prevalence due to such an environment. This is considered a good point of this study.

As mentioned above, the circumstances and environment of the area investigated in this study have not changed much over 30 years, with the same urban area, culture, and environmental factors. This point should also be considered when designing future studies.

\section{Conclusions}

Investigation of the correlations between annual changes in the prevalence of BA or wheezing among first-grade elementary school children (6 or 7 years old) and changes in the concentrations of air pollutants ( $\mathrm{SPM}, \mathrm{NO}, \mathrm{NO}_{2}$, and smoking rate) revealed the following points; in boys, BA correlated with $\mathrm{SPM}, \mathrm{NO}, \mathrm{NO}_{2}$, and smoking rate. Wheezing showed a similar tendency. In girls, wheezing was correlated with SPM, NO, $\mathrm{NO}_{2}$, and smoking rate, but $\mathrm{BA}$ was unrelated to any of the pollutants. There was no relationship between remission of $\mathrm{BA}$ and any of the pollutants. 
A recent decrease of asthma prevalence in this area might be related to the decreasing tendency of air pollutants concentration.

Acknowledgments: We would like to thank for Rintaro Ono, Yuki Okamoto and other doctors for their cooperation in visiting schools, and many children and their caregivers for their cooperation to complete the questionnaire. We also thank the many schoolteachers who have collected questionnaires over the years, and we thank Misako Yamamoto, Mie Katsumura and other secretaries for their contribution to data gathering.

Authors' contributions: H. Odajima designed the study. T. Kawano, M. Wakatsuki, Y. Akaminea, K. Okabe, T. Oki, H. Matsuzaki, Y. Murakami, M. Iwata, N. Taba, C. Moromura, S. Honjo and T. Ninomiya helped gather the questionnaire data.

Conflict of interest: None declared.

\section{References}

1 Innes Asher M, Montefort S, Björkstén B, et al. Worldwide time trends in prevalence of symptoms of asthma, allergic rhino conjunctivitis, and eczema in childhood: ISAAC phase one and three report multicounty cross-sectional survey. Lancet 2006; 368: 733-743.

2 Nishima S, Odajima H, Ota K, et al. A study on the prevalence of allergic diseases in school children in west districts of Japan-comparison between the studies in 1992, 2002 and 2012 with the same methods and same districts. Jpn J Pediatr Allergy 2013; 27: 149-169.

3 Environmental Health Department, Japanese Ministry of the Environment. Report of environmental health surveillance related to air pollution, 2018.

4 Ferris BG. Epidemiology standardization project. II. Recommended respiratory disease questionnaires for use with adults and children in epidemiological research. Am Rev Respir Dis 1978; 118: 7-53.

5 National Institute for Environmental Studies. Environmental numerical database, http://www.nines.go.jp. Date last accessed: August 16 2019. Date last updated: August 162019.

$6 \quad$ Guarnieri M, Balmes JR. Outdoor air pollution and asthma. Lancet 2014; 383: 1581-1592.

7 Schwartz J, Neas LM. Fine particulates are more strongly associated than coarse particulates with acute respiratory health effects in school children. Epidemiology 2000; 11: 6-10.

8 Roemer W, Hoek G, Brunekreef B. Effect of ambient winter air pollution on respiratory health of children with chronic respiratory symptoms. Am Rev Respir Dis 1993; 147: 118-124.

9 Liu C, Chen R, Sera F, et al. Ambient particulate air pollution and daily mortality in 652 cities. N Engl J Med 2019; 381: 705-715.

10 Odajima $\mathrm{H}$, Hirose T, Nishima S. Air pollution $\left(\mathrm{NO}_{2}\right.$, suspended particulate material) and the number of acute hospitalization of patients with asthmatic attack. Jpn J Allergol 1995; 44: 160-169.

11 Ueda K, Nitta H, Odajima H. The effects of weather, air pollutants, and Asian dust on hospitalization for asthma in Fukuoka. Environ Health Prev Med 2010; 15: 350-357.

12 Hasunuma H, Yamazaki S, Tamaru K, et al. Association between daily ambient air pollution and respiratory symptoms in children with asthma and healthy children in western Japan. J Asthma 2017; 54: 1-8.

13 Lee SH, Lee KW, Hwang YH, et al. The effect of short-term particular matter 2.5 exposure on asthma attacks in asthma children in Fukuoka. Japan. Kosin Med J 2018; 33: 171-180.

14 Odajima H, Yamazaki S, Nitta H. Decline in peak expiratory flow according to hourly short-term concentration of particulate matter in asthmatic children. Inhal Toxicol 2008; 20: 1-10.

15 Nishima S, Chisaka H, Fujiwara T, et al. Surveys on the prevalence of pediatric bronchial asthma in Japan: a comparison between the 1982, 1992, and 2002 surveys conducted in the same region using the same methodology. Allergol Int 2009; 58: 37-53.

16 Matsumoto I, Odajima H, Nishima S, et al. Change in prevalence of allergic diseases in primary school children aged 6-7 years, in Fukuoka city for the last 15 years. Jpn J Allergol 1999; 48: 435-442.

17 Ministry of Education, and Culture, Sports, Science and Technology, Japan. School Health Statistics Survey Report. www.mext.go.jp/en/. Date last accessed: July 4 2019. Date last updated: June 32019.

18 Nishima S, Odajima H. Prevalence of childhood allergic diseases in Japan using international study of asthma and allergies in childhood (ISAAC) phase I protocol. Jpn J Pediatr Allergy Clin Immunol 2002; 16: 207-220.

19 Odajima $\mathrm{H}$. The prevalence of asthma and allergic diseases in childhood $\sim$ changes in recent 10 years and childhood regional differences in the west Japan. Environmental Restoration and Conservation Organization 2013 report, 143-174, 2013.

20 Hasunuma H, Sato T, Iwata T, et al. Association between traffic-related air pollution and asthma in preschool children in a national Japanese nested case-control study. BMJ Open 2016; 6: e010410. .

21 Nakamura $\mathrm{T}$, Hashizume $\mathrm{M}$, Ueda $\mathrm{K}$, et al. Asian dust and pediatric emergency department visits due to bronchial asthma and respiratory diseases in Nagasaki, Japan. J Epidemiol 2016; 26: 593-601.

22 Okabe Y, Adachi Y, Itazawa T, et al. Association between obesity and asthma in Japanese preschool children. Pediatr Allergy Immunol 2012; 23: 550-555. 